\title{
Pretreatment patient-reported cognitive function in patients with diffuse glioma
}

\author{
Stine Schei ${ }^{1,2}$ (1) Ole Solheim ${ }^{3,4} \cdot \emptyset_{\text {yvind Salvesen }}{ }^{5}$. Marianne Jensen Hjermstad ${ }^{6,7,8}$. David Bouget ${ }^{9}$. \\ Lisa Millgård Sagberg ${ }^{1,4}$
}

Received: 8 October 2021 / Accepted: 10 January 2022 / Published online: 10 February 2022

(c) The Author(s) 2022

\begin{abstract}
Purpose Cognitive function is frequently assessed with objective neuropsychological tests, but patient-reported cognitive function is less explored. We aimed to investigate the preoperative prevalence of patient-reported cognitive impairment in patients with diffuse glioma compared to a matched reference group and explore associated factors.

Methods We included 237 patients with diffuse glioma and 474 age- and gender-matched controls from the general population. Patient-reported cognitive function was measured using the cognitive function subscale in the European Organisation for Research and Treatment of Cancer QLQ-C30 questionnaire. The transformed scale score (0-100) was dichotomized, with a score of $\leq 75$ indicating clinically important patient-reported cognitive impairment. Factors associated with preoperative patient-reported cognitive impairment were explored in a multivariable regression analysis.

Results Cognitive impairment was reported by $49.8 \%$ of the diffuse glioma patients and by $23.4 \%$ in the age- and gendermatched reference group $(p<0.001)$. Patients with diffuse glioma had 3.2 times higher odds (95\% CI 2.29, 4.58, $p<0.001$ ) for patient-reported cognitive impairment compared to the matched reference group. In the multivariable analysis, large tumor volume, left tumor lateralization, and low Karnofsky Performance Status score were found to be independent predictors for preoperative patient-reported cognitive impairment.

Conclusions Our findings demonstrate that patient-reported cognitive impairment is a common symptom in patients with diffuse glioma pretreatment, especially in patients with large tumor volumes, left tumor lateralization, and low functional levels. Patient-reported cognitive function may provide important information about patients' subjective cognitive health and disease status and may serve as a complement to or as a screening variable for subsequent objective testing.
\end{abstract}

Keywords Brain neoplasms $\cdot$ Cognition $\cdot$ Glioma $\cdot$ Patient-reported outcome measures $\cdot$ Preoperative period

$\begin{array}{llll}\text { Abbreviations } & \text { MRI } & \text { Magnetic resonance imaging } \\ \text { EORTC } & \text { European Organisation for Research and Treat- } & \text { 3D } & \text { Three-dimensional } \\ & \text { ment of Cancer } & \text { FLAIR } & \text { Fluid-attenuated inversion recovery } \\ \text { KPS } & \text { Karnofsky Performance Status } & \text { CI } & \text { Confidence interval } \\ \text { CCI } & \text { Charlson comorbidity index } & \text { OR } & \text { Odds ratio }\end{array}$

Stine Schei

stine.schei@ntnu.no

1 Department of Public Health and Nursing, Norwegian University of Science and Technology, Trondheim, Norway

2 Department of Neurology, St. Olavs hospital, Trondheim, Norway

3 Department of Neuromedicine and Movement Science, Norwegian University of Science and Technology, Trondheim, Norway

4 Department of Neurosurgery, St. Olavs hospital, Trondheim, Norway
5 Unit for Applied Clinical Research, Department of Clinical and Molecular Medicine, Norwegian University of Science and Technology, Trondheim, Norway

6 Regional Advisory Unit in Palliative Care, Department of Oncology, Oslo University Hospital, Oslo, Norway

7 European Palliative Care Research Centre, Department of Oncology, Oslo University Hospital, Oslo, Norway

8 Institute of Clinical Medicine, University of Oslo, Oslo, Norway

9 Department of Health Research, SINTEF Digital, Trondheim, Norway 


\section{Introduction}

Diffuse glioma is the most common primary malignant brain tumor in adults [36]. Cognitive impairment is a frequent symptom in glioma patients already before treatment [45]. This has a negative effect on patients' and relatives' quality of life $[3,38]$ and is independently associated with poor prognosis $[28,47]$. That underlines the importance of detecting cognitive impairment and developing or tailoring treatments that preserve cognitive functions in this patient group. Unfortunately, cognitive difficulties are often underestimated and overlooked by clinicians [12].

Neuropsychological assessments with objective tests have been viewed as the gold standard of cognitive evaluation in glioma studies, but these may be lengthy, time-consuming, and burdensome for the patients, especially in unselected high-grade glioma patients. This may result in poor compliance and selection bias [4, 5, 17, 23]. Furthermore, extensive neurocognitive testing is primarily performed in small samples of selected patients with tumor location in specific brain areas and/ or with specific symptoms $[39,45]$. As a result, the generalizability of findings to the unselected brain tumor population may suffer. Importantly, objective tests do not necessarily reflect the patient's subjective complaints. Therefore, in oncological glioma studies, the patient-reported cognitive function has been integrated to aid in establishing the net clinical benefit of oncological treatment [2, 21, 48], but assessments done before treatment are so far limited. Most available studies are also restricted to either cross-sectional design, lack of control groups, heterogeneous populations, or non-validated questionnaires [8, 10, 37, 43].

In the present study, we aimed to investigate the prevalence of preoperative patient-reported cognitive impairment in patients undergoing primary surgery for diffuse glioma compared to gender- and age-matched reference data from the Norwegian general population. Furthermore, we wanted to explore patient- and tumor-related factors that were associated with worse preoperative patientreported cognitive function.

\section{Methods}

\section{Study population}

In this study, all patients with diffuse glioma aged $\geq 18$ years scheduled for first time surgical resection or diagnostic biopsy at the Department of Neurosurgery,
St. Olavs hospital, Trondheim University Hospital (Norway) from September 2011 to December 2019, were eligible for inclusion. This department serves a defined geographic catchment area with a population of approximately 750,000, ensuring population-based referral. All tumors were histopathologically verified as grade II-IV glioma according to the 2007 or 2016 World Health Organization classification [31, 32]. Exclusion criteria were known dementia. A total of 237 (63\%) diffuse glioma patients were included in the analysis, and the inclusion process is presented in Fig. 1. The median age was 61 years (range 18-83 years), and 84 (35\%) were females. Most patients had high-grade glioma (79\%) and were functionally independent with a preoperative Karnofsky Performance Status (KPS) score $\geq 70$ (86\%). Only 5\% had severe comorbidities (Table 1).

\section{Variables and data collection}

All data were prospectively collected in a registry or as part of another project. Patient-reported cognitive function was measured using the cognitive function scale in the Norwegian-translated European Organisation for Research and Treatment of Cancer (EORTC) QLQ-C30 questionnaire (version 3) [1], which was completed 1-3 days before surgery by the patients themselves or with assistance from a nurse or family member. The cognitive function subscale includes two questions about concentration and memory. The time frame is the past week, and the questions are answered on a four-point scale from "not at all" to "very much."

The KPS was rated prospectively by the operating neurosurgeon just before surgery [33]. In six patients, prospective KPS was missing and medical notes were used

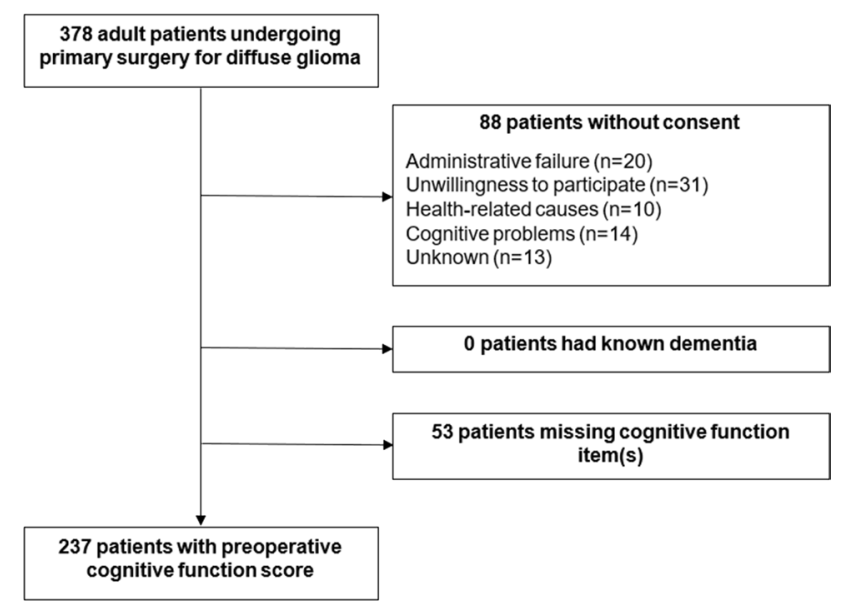

Fig. 1 Flowchart showing the inclusion process 
Table 1 Patient and tumor characteristics

\begin{tabular}{ll}
\hline & $N=237(100)$ \\
\hline Age in years, median (range) & $61(18-83)$ \\
Female, $n(\%)$ & $84(35)$ \\
Histopathology, $n(\%)$ & \\
Diffuse low-grade glioma & $49(21)$ \\
High-grade glioma & $188(79)$ \\
Tumor lateralization, $n(\%)$ & \\
Right & $116(49)$ \\
Left & $116(49)$ \\
Bilateral & $5(2)$ \\
Tumor location, $n(\%)$ & \\
Frontal & $72(30)$ \\
Temporal & $44(19)$ \\
Parietal & $13(6)$ \\
Occipital & $2(1)$ \\
Cerebellum/brainstem & $2(1)$ \\
Deep cerebral & \\
Multiple lobes & $6(2)$ \\
Preoperative Karnofsky Performance Status & $98(41)$ \\
$\quad$ score $\geq 70, n(\%)$ & $203(86)$ \\
Charlson Comorbidity Index $\geq 2, n(\%)$ & $12(5)$ \\
Preoperative use of corticosteroids, $n(\%)$ & $159(67)$ \\
Preoperative use of antiepileptic drugs, $n(\%)$ & $74(31)$ \\
Preoperative tumor volume ml, median (range) & $26.77(0.75-210.09)$ \\
\hline
\end{tabular}

${ }^{a}$ Basal ganglia/thalamus/corpus callosum/insula.

${ }^{\mathrm{b}} N=235$ due to 2 missing MRI.

to retrospectively estimate if the patients were functionally dependent $(<70)$ or independent $(\geq 70)$. Patient and treatment characteristics were collected from electronic medical records, and Charlson Comorbidity Index (CCI) was used to classify comorbidity [7]. Severe comorbidity was defined as $\mathrm{CCI} \geq 2$. Tumor volumes were estimated by semi-automatic tumor segmentation of MRIs using the software packages 3D Slicer version 4.3.1-4.10 (3D Slicer, Boston, Massachusetts) [14], or Brain Voyager ${ }^{\mathrm{TM}}$ QX version 1.2 (Brain Innovation, Maastricht, the Netherlands). The volume of pathological contrast-enhancement and necrotic tissue within the contrast-enhancing borders were used in contrast-enhancing tumors, while the entire volume as seen in T2/FLAIR sequences was used in tumors without ring contrast-enhancement. Lateralization was categorized according to where the center of mass in each tumor was located, while multifocal bilateral tumors were categorized as a separate group. Location was categorized based on which lobe that was involved. Tumors located in several lobes were categorized into a separate group.

\section{Reference population}

An age- and gender-matched reference population was retrieved from previously collected representative sample data from the Norwegian population that was published in 1998 [26]. EORTC QLQ-C30 was sent out to 3000 Norwegian adults based on a random draw of all inhabitants. This population survey had a response rate of $66 \%$, and 1926 persons answered the two questions regarding cognitive function. The reference population was matched with the glioma population on age and gender with the ratio of $2: 1$. The ageand gender-matched reference group counted 474 individuals, where the median age was 60 (range 19-83 years), and $35 \%$ were females.

\section{Statistical analyses}

We used descriptive statistics to characterize the patients with diffuse glioma. Means are presented if data were normally distributed, while medians are presented if data were skewed.

The cognitive function questions were transformed into a 0-100 scale according to the EORTC scoring manual [13], with a cutoff of $\leq 75$ indicating clinically important patientreported cognitive impairment [20]. We examined dependence between cognitive function within matched triples using a mixed logistic regression model, with group as fixed effect and matched triple as random effect. Since the variance of the random effect was estimated at zero, the matched analysis of cognitive function simplified to an unmatched analysis. Therefore, Clopper-Pearson confidence interval (CI) for cognitive impairment proportion and Fisher's exact test were used for comparing the diffuse glioma population with the reference population.

To investigate variables possibly associated with preoperative patient-reported cognitive impairment in patients with diffuse glioma, we used binary logistic regression analysis. Variables with a statistical trend $(p<0.1)$ in a univariable model were included in the final multivariable model. In all analyses, $p$-values $\leq 0.05$ were considered statistically significant. The analyses were performed in $\mathrm{R}$ version 3.6.3 using the package lme4 (R Foundation for Statistical Computing, Vienna, Austria) and IBM SPSS Statistics for Windows, version 26 (IBM Corp., Armonk, N.Y., USA).

\section{Ethics}

This study was approved by the Regional Committee for Medical and Health Research Ethics in South and East Norway (reference number 67005). All glioma patients provided written informed consent as part of other projects (reference number 2011/974 or 2015/215), and the data collection followed the Helsinki Declaration principles. 


\section{Results}

\section{Comparison between diffuse glioma patients and matched reference group}

As shown in Table 2, 49.8\% of the patients had a preoperative cognitive score $\leq 75$, indicating a clinically important patient-reported cognitive impairment, compared to $23.4 \%$

Table 2 Proportion (95\% CI) of clinically important patient-reported cognitive impairment in diffuse glioma patients and the matched reference group

\begin{tabular}{llll}
\hline $\begin{array}{l}\text { Diffuse glioma } \\
\text { patients }\end{array}$ & Reference group & OR (95\% CI) & $P$-value \\
\hline $118 / 237$ & $111 / 474$ & $3.24(2.29,4.58)$ & $<0.001^{*}$ \\
$49.8 \%(43.3,56.3)$ & $23.4 \%(19.7,27.4)$ & & \\
\hline
\end{tabular}

*Indicates $p \leq 0.05$.

$O R$, odds ratio; $C I$, confidence interval. in the matched reference group $(p<0.001)$. Thus, patients with diffuse glioma had 3.2 times higher odds for selfreported cognitive impairment compared to the matched reference group.

\section{Possible predictors of preoperative patient-reported cognitive impairment}

In the univariable analyses, histopathology, tumor lateralization, KPS, use of corticosteroids, and tumor volume were factors significantly associated with patient-reported cognitive impairment $(p \leq 0.05)$, while there was a trend for gender $(p<0.1)$. When including these variables in a multivariable analysis, only tumor lateralization, KPS, and tumor volume remained significant independent predictors (Table 3). A tumor in the left hemisphere increased the odds for patient-reported cognitive impairment by 3.3 times compared to a tumor in the right hemisphere. For small tumors up to the 3rd quartile of volumes, there were increased odds for impairment with larger tumor volume, while increased
Table 3 Factors associated with patient-reported cognitive impairment in diffuse glioma patients

\begin{tabular}{|c|c|c|c|c|}
\hline \multirow[t]{2}{*}{ Variables in the binary regression model } & \multicolumn{2}{|c|}{ Univariable analyses } & \multicolumn{2}{|c|}{ Multivariable analyses } \\
\hline & OR $(95 \% \mathrm{CI})$ & $p$-value & OR $(95 \% \mathrm{CI})$ & $p$-value \\
\hline Age & $1.00(0.99,1.02)$ & 0.680 & & \\
\hline Female & $1.59(0.92,2.70)$ & $0.094 *$ & $1.83(0.98,3.41)$ & 0.058 \\
\hline High-grade glioma & $1.96(1.02,3.74)$ & $0.042 *$ & $1.07(0.43,2.67)$ & 0.890 \\
\hline Tumor lateralization & & $0.001 *$ & & $<0.001^{*}$ \\
\hline Right & Reference & & Reference & \\
\hline Left & $2.68(1.57,4.55)$ & $<0.001^{*}$ & $3.30(1.80,6.06)$ & $<0.001 *$ \\
\hline Bilateral & $1.09(0.17,6.79)$ & 0.926 & $0.54(0.08,3.56)$ & 0.519 \\
\hline Tumor location & & 0.478 & & \\
\hline Frontal & Reference & & & \\
\hline Temporal & $1.35(0.64,2.88)$ & 0.432 & & \\
\hline Parietal & $2.37(0.71,7.98)$ & 0.163 & & \\
\hline Occipital & - & - & & \\
\hline Cerebellum/brainstem & $1.48(0.09,24.67)$ & 0.784 & & \\
\hline Deep central & $0.74(0.13,4.32)$ & 0.739 & & \\
\hline Multiple lobes & $1.90(1.02,3.52)$ & $0.042 *$ & & \\
\hline Karnofsky Performance Status (continuous) ${ }^{\mathrm{a}}$ & $0.96(0.94,0.98)$ & $<0.001^{*}$ & $0.96(0.94,0.99)$ & $0.006^{*}$ \\
\hline Charlson Comorbidity Index $\geq 2$ & $0.71(0.22,0.30)$ & 0.565 & & \\
\hline Corticosteroids & $1.99(1.14,3.45)$ & $0.015^{*}$ & $1.04(0.46,2.38)$ & 0.918 \\
\hline Antiepileptic drugs & $0.74(0.42,1.28)$ & 0.282 & & \\
\hline Tumor volume $^{\mathrm{b}}$ & & $0.002 *$ & & $0.028 *$ \\
\hline$\leq 9.7 \mathrm{ml}$ & Reference & & Reference & \\
\hline $9.8-26.8 \mathrm{ml}$ & $1.78(0.84,3.76)$ & 0.133 & $1.76(0.77,4.05)$ & 0.179 \\
\hline $28.5-56.5 \mathrm{ml}$ & $4.43(2.04,9.60)$ & $<0.001^{*}$ & $3.93(1.60,9.69)$ & $0.003 *$ \\
\hline $56.9-210.1 \mathrm{ml}$ & $2.42(1.14,5.12)$ & $0.021 *$ & $1.88(0.74,4.75)$ & 0.184 \\
\hline
\end{tabular}

*Indicates $p \leq 0.05$.

$O R$, odds ratio; $C I$, confidence interval.

${ }^{\mathrm{a}} N=231$ due to 6 missing KPS score.

${ }^{\mathrm{b}}$ Quartiles. $N=235$ due to 2 missing MRI. 
KPS was associated with a slightly decreasing likelihood for reporting cognitive impairment. The concordance index, a measure of the predictive accuracy of the model, was 0.75 .

For KPS, there was a relationship where lower functional levels were associated with higher frequencies of patientreported cognitive impairment. Even in patients with normal functional levels (KPS 100), 37\% of the patients reported cognitive impairment (Table 4). The risk of patient-reported cognitive impairment was significantly higher in a subgroup of patients with normal or close to normal functions (KPS $90-100)$ compared to matched references ( $38 \%$ vs. $21 \%$, OR $2.27,95 \%$ CI $1.33,3.78, p=0.002$ ).

\section{Discussion}

In this study, we assessed pretreatment patient-reported cognitive impairment in patients with diffuse glioma. Almost half of the patients reported a clinically important cognitive impairment, which was more than two times as prevalent as in the matched reference group from the general population. Patient-reported cognitive impairment was also common in patients with normal or close to normal functional levels. Independent predictors for preoperative patientreported cognitive impairment were tumors located in the left hemisphere, large tumor volume, and lower functional levels. These findings indicate a potential validity of patientreported cognitive function in glioma patients.

The high prevalence of patient-reported cognitive impairment in our study is in line with findings in a systematic review of studies using objective neurocognitive tests that found cognitive impairment in approximately $60 \%$ of glioma patients before surgical treatment [45]. Even if there has been an increasing emphasis on incorporating patientreported data in neurosurgical clinical research in the last years, studies examining patient-reported cognitive function are still rare. In a cross-sectional study using the EORTC

Table 4 Frequency of patient-reported cognitive impairment across different functional levels

\begin{tabular}{lll}
\hline $\begin{array}{l}\text { Karnofsky Performance } \\
\text { Status score }\end{array}$ & $\begin{array}{l}\text { Clinically important cognitive impair- } \\
\text { ment }\end{array}$ \\
\cline { 2 - 3 } & $\begin{array}{l}\text { Yes }(N=115)^{\mathrm{a}} \\
n(\%)\end{array}$ & $\begin{array}{l}\text { No }(N=116)^{\mathrm{b}} \\
n(\%)\end{array}$ \\
\hline 100 & $13(37)$ & $22(63)$ \\
90 & $29(39)$ & $46(61)$ \\
80 & $22(48)$ & $24(52)$ \\
70 & $29(67)$ & $14(33)$ \\
60 & $13(62)$ & $8(38)$ \\
50 & $9(82)$ & $2(18)$ \\
\hline
\end{tabular}

${ }^{\mathrm{a}} N=115$ due to 3 missing KPS. ${ }^{\mathrm{b}} N=116$ due to 3 missing KPS. questionnaire in glioma patients before primary and recurrent surgery [8], cognitive impairment had a prevalence of $75 \%$. However, here, they had merged the social and cognitive function scales and did not report cutoff scores when defining cognitive impairment. Also, unstandardized assessments have been used in a small study of low-grade glioma patients where $33 \%$ reported preoperative problems with concentration the last year [10], and in a larger brain tumor study where $32 \%$ and $24 \%$ reported problems with memory and attention before treatment, respectively [43].

The high prevalence of patient-reported impairment in the glioma population is probably caused by a variety of factors. In neuropsychological studies, there is strong evidence that the tumor itself causes impairment [30], which in the present study also seems to apply to patient-reported impairment. Corticosteroids and antiepileptic drugs are other factors known to potentially contribute to declined objective cognitive function [23, 29], although we did not find any such associations with patient-reported function. Similarly, no association between patient-reported cognitive function and antiepileptic drugs was found in another study [44]. Additionally, the psychological effect of being diagnosed with a life-threatening disease and additional symptoms such as fatigue and sleep disturbance may hamper the patient's ability to concentrate and remember things [16, 18, 37, 40].

We found an increased risk of patient-reported cognitive impairment with increasing tumor volume up to the third quartile of volumes. A relationship between large tumor volume and/or mass effect and cognitive impairment is found in previous studies using objective tests as well $[19,23,25$, $42,46]$. Furthermore, better patient-reported cognitive functioning, as measured with EORTC cognitive function scale, is found to be independently associated with both overall survival and progression-free survival in glioma patients [11]. Thus, our results support what others have suggested, that patients' cognitive complaints may reflect tumor burden and may therefore be an indicator of the severity of the disease [11]. Interestingly, in our material, the risk of patient-reported cognitive impairment was somewhat lower in patients harboring the largest quartile of tumor volumes. Since few patients had very large tumor volume, this finding may be due to chance. Large tumors may also cause other symptoms overshadowing cognitive problems, such as nausea/vomiting, aphasia, and motor deficits, and are also more often located in the frontal lobe and may affect the patient's self-awareness [9].

Our findings suggest that tumors in the left hemisphere negatively affect patients' self-perceived cognitive function, and also in the literature, left-sided tumors appear to cause more severe objective cognitive deficits compared to right-sided tumors [23-25, 34]. However, damage in the right hemispheric is found to be associated with anosognosia $[35,41]$. Thus, it is reasonable to assume that patients 
with right-sided tumors report less subjective cognitive impairment due to impaired awareness. However, a recent study found no difference between self-awareness in HGG patients with left-sided and right-sided tumor lateralization [22]. Furthermore, an association between affected lobes and worse performance on specific objective tests has been reported $[19,25]$. Few patients in each lobe may explain why we did not find such association. In addition, since the EORTC questionnaire only contains two questions regarding memory and concentration, we acknowledge that this scale is not sensitive enough to detect all mental abilities or to provide a thorough assessment of patient-reported cognitive function. On the other hand, it gives an indication of a common patient problem that warrants further examination.

In our material, patient-reported cognitive impairment was common also in patients who, according to the surgeons, had more or less normal functional levels. This is important knowledge since subtle cognitive symptoms may have a large impact on patients' quality of life and ability to work. We also found that lower functional levels increased the risk of subjective cognitive impairment, which is in accordance with previous findings [8]. Our finding is not surprising since KPS does not distinguish among different types of performance limitations [28]. In addition, cognitive function and KPS share the same risk factors, such as higher age, high-grade histology, and larger tumor volume.

Patient-reported outcomes have not been validated to measure cognitive function in brain tumor patients, and there may be a low correlation between patient-reported data and objective neurocognitive assessment $[6,18]$. Thus, it is suggested not to use patient-reported outcomes as a surrogate of objective neuropsychological functioning [6]. Yet, this should not diminish the importance or relevance of the patient's subjective complaints, and several recommend using a combination of objective and patient-reported outcome measures of cognitive functioning [18, 27]. The clinical experience is that some patients experience a discrepancy between their present and previous cognitive function, even if the results from the neuropsychological tests are normal. Patient-reported questionnaires can be a practical tool to provide information about patients' cognitive health, especially in unselected patients who are not suitable for extensive neuropsychological testing.

The main strength of this study is the large prospective population-based data collection and the matched control group, increasing the generalizability of our findings. The study also has some limitations. First, we attempted to include unselected glioma patients, but cannot exclude an extent of selection bias and a potential underestimation of patient-reported cognitive impairment. Second, we did not have information about the patients' level of education or material status, which may be important factors for patientreported cognitive function. Furthermore, the reference material was published in 1998, but a national population survey was repeated in 2004 with similar scores on the EORTC cognitive function scale [15]. Additionally, even though the patients' self-awareness may perhaps be questionable, we argue that ratings from their perspective should not be ignored due to the significant impact on their quality of life. Moreover, two questions from the EORTC questionnaire do not capture all aspects of how patients experience their cognitive function, and more subtle impairments could probably be detected with a more detailed questionnaire. However, such a questionnaire may have been too complicated for our unselected glioma patients. At last, since some patients received assistance when scoring the questionnaire, we cannot exclude that the answers were influenced by others.

\section{Conclusion}

We investigated pretreatment patient-reported cognitive impairment in patients with diffuse glioma. We found that almost half of the diffuse glioma patients reported cognitive impairment before surgery, which was almost twice as much as in the general population. It was a common symptom also in patients with normal surgeon-reported functional levels. Independent predictors were left-sided tumors, large tumor volume, and lower functional levels. Patient-reported cognitive function may provide important information about unselected glioma patients' subjective cognitive health and disease status, and serve as a complement or a screening variable for subsequent objective testing.

Acknowledgements We would like to thank Camilla Brattbakk, Linda Nordtvedt, and Even Hovig Fyllingen for assisting in data collection.

Author contribution Conception and design: Stine Schei, Lisa Millgård Sagberg, Ole Solheim; data collection: Stine Schei, Lisa Millgård Sagberg, Ole Solheim, Marianne Jensen Hjermstad, David Bouget; statistical analysis: Stine Schei, Øyvind Salvesen; analysis and interpretation of data: Stine Schei, Lisa Millgård Sagberg, Ole Solheim, Øyvind Salvesen; drafting the article: Stine Schei, Lisa Millgård Sagberg, Ole Solheim; critically revising the article: all authors; reviewed submitted version of manuscript: all authors; approved the final version of the manuscript on behalf of all authors: Stine Schei; study supervision: Lisa Millgård Sagberg, Ole Solheim.

Funding Open access funding provided by NTNU Norwegian University of Science and Technology (incl St. Olavs Hospital - Trondheim University Hospital). The article was funded by the Faculty of Medicine and Health Sciences at the Norwegian University of Science and Technology.

Data availability The dataset generated during and/or analyzed during the current study is not publicly available due to privacy concerns but is available from the corresponding author on reasonable request. 


\section{Declarations}

Conflict of interest The authors declare no competing interests.

Open Access This article is licensed under a Creative Commons Attribution 4.0 International License, which permits use, sharing, adaptation, distribution and reproduction in any medium or format, as long as you give appropriate credit to the original author(s) and the source, provide a link to the Creative Commons licence, and indicate if changes were made. The images or other third party material in this article are included in the article's Creative Commons licence, unless indicated otherwise in a credit line to the material. If material is not included in the article's Creative Commons licence and your intended use is not permitted by statutory regulation or exceeds the permitted use, you will need to obtain permission directly from the copyright holder. To view a copy of this licence, visit http://creativecommons.org/licenses/by/4.0/.

\section{References}

1. Aaronson NK, Ahmedzai S, Bergman B, Bullinger M, Cull A, Duez NJ, Filiberti A, Flechtner H, Fleishman SB, de Haes JC (1993) The European Organization for Research and Treatment of Cancer QLQ-C30: a quality-of-life instrument for use in international clinical trials in oncology. JNCI: J Natl Cancer Inst 85:365-376. https://doi.org/10.1093/jnci/85.5.365

2. Armstrong TS, Wefel JS, Wang M, Gilbert MR, Won M, Bottomley A, Mendoza TR, Coens C, Werner-Wasik M, Brachman DG (2013) Net clinical benefit analysis of radiation therapy oncology group 0525: a phase III trial comparing conventional adjuvant temozolomide with dose-intensive temozolomide in patients with newly diagnosed glioblastoma. J Clin Oncol 31:4076. https://doi. org/10.1200/JCO.2013.49.6067

3. Boele FW, Zant M, Heine ECE, Aaronson NK, Taphoorn MJB, Reijneveld JC, Postma TJ, Heimans JJ, Klein M (2014) The association between cognitive functioning and health-related quality of life in low-grade glioma patients. Neuro-Oncology Practice 1:40-46. https://doi.org/10.1093/nop/npu007

4. Brown PD, Ballman KV, Cerhan JH, Anderson SK, Carrero XW, Whitton AC, Greenspoon J, Parney IF, Laack NNI, Ashman JB, Bahary J-P, Hadjipanayis CG, Urbanic JJ, Barker FG, Farace E, Khuntia D, Giannini C, Buckner JC, Galanis E, Roberge D (2017) Postoperative stereotactic radiosurgery compared with whole brain radiotherapy for resected metastatic brain disease (NCCTG N107C/CEC.3): a multicentre, randomised, controlled, phase 3 trial. Lancet Oncol 18:1049-1060. https://doi.org/10.1016/S14702045(17)30441-2

5. Brown PD, Gondi V, Pugh S, Tome WA, Wefel JS, Armstrong TS, Bovi JA, Robinson C, Konski A, Khuntia D, Grosshans D, Benzinger TLS, Bruner D, Gilbert MR, Roberge D, Kundapur V, Devisetty K, Shah S, Usuki K, Anderson BM, Stea B, Yoon H, Li J, Laack NN, Kruser TJ, Chmura SJ, Shi W, Deshmukh S, Mehta MP, Kachnic LA, Oncology fN, (2020) Hippocampal avoidance during whole-brain radiotherapy plus memantine for patients with brain metastases: phase III trial NRG oncology CC001. J Clin Oncol 38:1019-1029. https://doi.org/10.1200/jco.19.02767

6. Caramanna I, Bottomley A, Drijver AJ, Twisk J, van den Bent M, Idbaih A, Wick W, Pe M, Klein M, Reijneveld JC (2020) Objective neurocognitive functioning and neurocognitive complaints in patients with high-grade glioma: evidence of cognitive awareness from the European Organisation for Research and Treatment of Cancer brain tumour clinical trials. Eur J Cancer 144:162-168. https://doi.org/10.1016/j.ejca.2020.10.040
7. Charlson ME, Pompei P, Ales KL, MacKenzie CR (1987) A new method of classifying prognostic comorbidity in longitudinal studies: development and validation. J Chronic Dis 40:373-383. https://doi.org/10.1016/0021-9681(87)90171-8

8. Cheng J-x, Liu B-1, Zhang X, Lin W, Zhang Y-q, Liu W-p, Zhang J-n, Lin H, Wang R, Yin H (2010) Health-related quality of life in glioma patients in China. BMC Cancer 10:1-8. https://doi.org/ 10.1186/1471-2407-10-305

9. Chow TW (2000) Personality in frontal lobe disorders. Curr Psychiatry Rep 2:446-451. https://doi.org/10.1007/ s11920-000-0031-5

10. Cochereau J, Herbet G, Duffau H (2016) Patients with incidental WHO grade II glioma frequently suffer from neuropsychological disturbances. Acta Neurochir (Wien) 158:305-312. https://doi. org/10.1007/s00701-015-2674-3

11. Coomans M, Dirven L, Aaronson NK, Baumert BG, van den Bent M, Bottomley A, Brandes AA, Chinot O, Coens C, Gorlia $\mathrm{T}$ (2019) The added value of health-related quality of life as a prognostic indicator of overall survival and progression-free survival in glioma patients: a meta-analysis based on individual patient data from randomised controlled trials. Eur J Cancer 116:190-198. https://doi.org/10.1016/j.ejca.2019.05.012

12. Drewes C, Sagberg LM, Jakola AS, Gulati S, Solheim O (2015) Morbidity after intracranial tumor surgery: sensitivity and specificity of retrospective review of medical records compared with patient-reported outcomes at 30 days. J Neurosurg 123:972977. https://doi.org/10.3171/2014.12.JNS142206

13. Fayers P, Aaronson NK, Bjordal K, Groenvold M, Curran D, Bottomley A (2001) EORTC QLQ-C30 Scoring manual, 3rd edn. European Organisation for Research and Treatment og Cancer, Brussels

14. Fedorov A, Beichel R, Kalpathy-Cramer J, Finet J, FillionRobin J-C, Pujol S, Bauer C, Jennings D, Fennessy F, Sonka M, Buatti J, Aylward S, Miller JV, Pieper S, Kikinis R (2012) 3D Slicer as an image computing platform for the Quantitative Imaging Network. Magn Reson Imaging 30:1323-1341. https:// doi.org/10.1016/j.mri.2012.05.001

15. Fosså SD, Lothe Hess S, Dahl AA, Hjermstad MJ, Veenstra M (2007) Stability of health-related quality of life in the Norwegian general population and impact of chronic morbidity in individuals with and without a cancer diagnosis. Acta Oncol 46:452-461. https://doi.org/10.1080/02841860601182641

16. Fox SW, Lyon D, Farace E (2007) Symptom clusters in patients with high-grade glioma. J Nurs Scholarsh 39:61-67

17. Froklage FE, Oosterbaan LJ, Sizoo EM, de Groot M, Bosma I, Sanchez E, Douw L, Heimans J, Reijneveld J, Lagerwaard F (2014) Central neurotoxicity of standard treatment in patients with newly-diagnosed high-grade glioma: a prospective longitudinal study. J Neurooncol 116:387-394

18. Gehring K, Taphoorn MJB, Sitskoorn MM, Aaronson NK (2015) Predictors of subjective versus objective cognitive functioning in patients with stable grades II and III glioma. Neurooncology practice 2:20-31. https://doi.org/10.1093/nop/npu035

19. Gempt J, Lange N, Bette S, Foreman SC, Cammardella JH, Albertshauser J, Gradtke C, Buchmann N, Ryang Y-M, SchmidtGraf F (2017) Factors influencing neurocognitive function in patients with neuroepithelial tumors. Sci Rep 7:1-10. https:// doi.org/10.1093/neuonc/nox 168

20. Giesinger JM, Loth FLC, Aaronson NK, Arraras JI, Caocci G, Efficace F, Groenvold M, van Leeuwen M, Petersen MA, Ramage J, Tomaszewski KA, Young T, Holzner B (2020) Thresholds for clinical importance were established to improve interpretation of the EORTC QLQ-C30 in clinical practice and research. J Clin Epidemiol 118:1-8. https://doi.org/10.1016/j. jclinepi.2019.10.003 
21. Gilbert MR, Dignam JJ, Armstrong TS, Wefel JS, Blumenthal DT, Vogelbaum MA, Colman H, Chakravarti A, Pugh S, Won M, Jeraj R, Brown PD, Jaeckle KA, Schiff D, Stieber VW, Brachman DG, Werner-Wasik M, Tremont-Lukats IW, Sulman EP, Aldape KD, Curran WJ, Mehta MP (2014) A randomized trial of bevacizumab for newly diagnosed glioblastoma. N Engl J Med 370:699-708. https://doi.org/10.1056/NEJMoa1308573

22. Giovagnoli AR, Meneses RF, Paterlini C, Silvani A, Boiardi A (2021) Cognitive awareness after treatment for high-grade glioma. Clin Neurol Neurosurg 210:106953. https://doi.org/10.1016/j. clineuro.2021.106953

23. Habets EJJ, Kloet A, Walchenbach R, Vecht CJ, Klein M, Taphoorn MJB (2014) Tumour and surgery effects on cognitive functioning in high-grade glioma patients. Acta Neurochir (Wien) 156:1451-1459. https://doi.org/10.1007/s00701-014-2115-8

24. Hahn CA, Dunn RH, Logue PE, King JH, Edwards CL, Halperin EC (2003) Prospective study of neuropsychologic testing and quality-of-life assessment of adults with primary malignant brain tumors. International Journal of Radiation Oncology*Biology*Physics 55:992-999. https://doi.org/10.1016/ S0360-3016(02)04205-0

25. Hendrix P, Hans E, Griessenauer CJ, Simgen A, Oertel J, Karbach J (2017) Neurocognitive status in patients with newly-diagnosed brain tumors in good neurological condition: the impact of tumor type, volume, and location. Clin Neurol Neurosurg 156:55-62. https://doi.org/10.1016/j.clineuro.2017.03.009

26. Hjermstad MJ, Fayers PM, Bjordal K, Kaasa S (1998) Healthrelated quality of life in the general Norwegian population assessed by the European Organization for Research and Treatment of Cancer Core Quality-of-Life Questionnaire: the QLQ= C30 (+ 3). J Clin Oncol 16:1188-1196. https://doi.org/10.1200/ JCO.1998.16.3.1188

27. Hutchinson AD, Hosking JR, Kichenadasse G, Mattiske JK, Wilson C (2012) Objective and subjective cognitive impairment following chemotherapy for cancer: a systematic review. Cancer Treat Rev 38:926-934. https://doi.org/10.1016/j.ctrv.2012.05.002

28. Johnson DR, Sawyer AM, Meyers CA, O'Neill BP, Wefel JS (2012) Early measures of cognitive function predict survival in patients with newly diagnosed glioblastoma. Neuro Oncol 14:808-816. https://doi.org/10.1093/neuonc/nos082

29. Klein M, Taphoorn MJ, Heimans JJ, van der Ploeg HM, Vandertop WP, Smit EF, Leenstra S, Tulleken CA, Boogerd W, Belderbos JS (2001) Neurobehavioral status and health-related quality of life in newly diagnosed high-grade glioma patients. J Clin Oncol 19:4037-4047. https://doi.org/10.1200/JCO.2001.19.20.4037

30. Klein M, Duffau H, Hamer PCDW (2012) Cognition and resective surgery for diffuse infiltrative glioma: an overview. J Neurooncol 108:309-318. https://doi.org/10.1007/s11060-012-0811-x

31. Louis DN, Ohgaki H, Wiestler OD, Cavenee WK, Burger PC, Jouvet A, Scheithauer BW, Kleihues P (2007) The 2007 WHO Classification of Tumours of the Central Nervous System. Acta Neuropathol 114:97-109. https://doi.org/10.1007/s00401-007-0243-4

32. Louis DN, Perry A, Reifenberger G, von Deimling A, FigarellaBranger D, Cavenee WK, Ohgaki H, Wiestler OD, Kleihues P, Ellison DW (2016) The 2016 World Health Organization Classification of Tumors of the Central Nervous System: a summary. Acta Neuropathol 131:803-820. https://doi.org/10.1007/ s00401-016-1545-1

33. Mor V, Laliberte L, Morris JN, Wiemann M (1984) The Karnofsky performance status scale: an examination of its reliability and validity in a research setting. Cancer 53:2002-2007

34. Noll KR, Ziu M, Weinberg JS, Wefel JS (2016) Neurocognitive functioning in patients with glioma of the left and right temporal lobes. J Neurooncol 128:323-331. https://doi.org/10.1007/ s11060-016-2114-0
35. Orfei MD, Robinson RG, Prigatano GP, Starkstein S, Rüsch N, Bria P, Caltagirone C, Spalletta G (2007) Anosognosia for hemiplegia after stroke is a multifaceted phenomenon: a systematic review of the literature. Brain 130:3075-3090. https://doi.org/10. 1093/brain/awm106

36. Ostrom QT, Patil N, Cioffi G, Waite K, Kruchko C, BarnholtzSloan JS (2020) CBTRUS statistical report: primary brain and other central nervous system tumors diagnosed in the United States in 2013-2017. Neuro-Oncology 22:iv1-iv96. https://doi. org/10.1093/neuonc/noaa200

37. Pranckeviciene A, Deltuva VP, Tamasauskas A, Bunevicius A (2017) Association between psychological distress, subjective cognitive complaints and objective neuropsychological functioning in brain tumor patients. Clin Neurol Neurosurg 163:18-23. https://doi.org/10.1016/j.clineuro.2017.10.007

38. Schubart JR, Kinzie MB, Farace E (2008) Caring for the brain tumor patient: family caregiver burden and unmet needs. Neuro Oncol 10:61-72. https://doi.org/10.1215/15228517-2007-040

39. Sinha R, Stephenson JM, Price SJ (2020) A systematic review of cognitive function in patients with glioblastoma undergoing surgery. Neuro-Oncology Practice 7:131-142. https://doi.org/10. 1093/nop/npz018

40. Sterckx W, Coolbrandt A, de Casterlé BD, Van den Heede K, Decruyenaere M, Borgenon S, Mees A, Clement P (2013) The impact of a high-grade glioma on everyday life: a systematic review from the patient's and caregiver's perspective. Eur J Oncol Nurs 17:107-117

41. Steward KA, Kretzmer T (2021) Anosognosia in moderate-tosevere traumatic brain injury: a review of prevalence, clinical correlates, and diversity considerations. The Clinical Neuropsychologist:1-20. https://doi.org/10.1080/13854046.2021.1967452

42. Talacchi A, Santini B, Savazzi S, Gerosa M (2011) Cognitive effects of tumour and surgical treatment in glioma patients. J Neurooncol 103:541-549. https://doi.org/10.1007/s11060-010-0417-0

43. Tucha O, Smely C, Preier M, Lange KW (2000) Cognitive deficits before treatment among patients with brain tumors. Neurosurgery 47:324-334. https://doi.org/10.1097/00006123-200008000-00011

44. van der Meer PB, Koekkoek JAF, van den Bent MJ, Dirven L, Taphoorn MJB (2021) Effect of antiepileptic drugs in glioma patients on self-reported depression, anxiety, and cognitive complaints. J Neurooncol 153:89-98. https://doi.org/10.1007/ s11060-021-03747-1

45. van Kessel E, Baumfalk AE, van Zandvoort MJ, Robe PA, Snijders TJ (2017) Tumor-related neurocognitive dysfunction in patients with diffuse glioma: a systematic review of neurocognitive functioning prior to anti-tumor treatment. J Neurooncol 134:9-18. https://doi.org/10.1007/s11060-017-2503-Z

46. Van Kessel E, Emons MAC, Wajer IH, Van Baarsen KM, Broekman ML, Robe PA, Snijders TJ, Van Zandvoort MJE (2019) Tumor-related neurocognitive dysfunction in patients with diffuse glioma: a retrospective cohort study prior to antitumor treatment. Neuro-Oncology Practice 6:463-472. https://doi.org/10.1093/nop/ npz008

47. van Kessel E, Wajer IMH, Ruis C, Seute T, Fonville S, De Vos FY, Verhoeff JJ, Robe PA, van Zandvoort MJ, Snijders TJ (2021) Cognitive impairments are independently associated with shorter survival in diffuse glioma patients. J Neurol 268:1434-1442

48. Zhu J-J, Demireva P, Kanner AA, Pannullo S, Mehdorn M, Avgeropoulos N, Salmaggi A, Silvani A, Goldlust S, David C, Benouaich-Amiel A, Zvi Ram on behalf of the EFTI (2017) Health-related quality of life, cognitive screening, and functional status in a randomized phase III trial (EF-14) of tumor treating fields with temozolomide compared to temozolomide alone in newly diagnosed glioblastoma. J Neurooncol 135:545-552. https://doi.org/10.1007/s11060-017-2601-y 


\section{Comments}

In contrast to most other reports concerning cognitive function in patients with diffuse glioma, the authors of the present article did not use any psychometric neuropsychological tests. Thus they exclusively applied a cognitive subscale in the European organization for research and treatment of cancer, QLQ-C30 questionnaire. The aim was to investigate the prevalence of subjectively experienced cognitive deficits, according to the mentioned questionnaire, in diffuse glioma patients before primary surgery, in comparison to a gender- and agematched reference group from the Norwegian general population. In addition the authors intended to explore patient- and tumor-related factors associated with worse preoperative patient-reported cognitive function. The frequency of self-reported significant cognitive impairment in the patient group, was two times higher than in the reference group. Furthermore, independent predictors for patientreported cognitive impairment before surgery, turned out to be tumors located in the left hemisphere, large tumor volume and lower functional levels.
This study is of interest since it suggests that the selfreported cognitive function in diffuse glioma patients before surgical treatment, used as a screening and complement to the objective clinical investigation, possibly provides valid information and could give preliminary hints about the disease status as well as guidance for decisions concerning psychometric neuropsychological testing.

\section{Åsa Bergendal}

Stockholm, Sweden

Publisher's note Springer Nature remains neutral with regard to jurisdictional claims in published maps and institutional affiliations. 